\title{
The Pandemic Stressor Scale - Factorial Validity and Reliability of a Measure of Stressors During a Pandemic
}

\author{
Annett Lotzin ( $\sim$ A.Lotzin@uke.de) \\ University Medical Center Hamburg- Eppendorf \\ Ronja Ketelsen \\ University Medical Center Hamburg- Eppendorf \\ Irina Zmic \\ University of Vienna \\ Brigitte Lueger-Schuster \\ University of Vienna \\ Maria Böttche \\ Freie Universität Berlin \\ Ingo Schäfer \\ University Medical Center Hamburg- Eppendorf
}

\begin{abstract}
Research Article
Keywords: COVID-19, pandemic, stressors, psychometrics
\end{abstract}

Posted Date: July 26th, 2021

DOI: https://doi.org/10.21203/rs.3.rs-555631/v1

License: () (1) This work is licensed under a Creative Commons Attribution 4.0 International License. Read Full License

Version of Record: A version of this preprint was published at BMC Psychology on April 8th, 2022. See the published version at https://doi.org/10.1186/s40359-022-00790-z. 


\section{Abstract}

Background: This study aimed to assess the factorial validity and reliability of the Pandemic Stressor Scale (PaSS), a new measure to assess the severity of distress for different stressors relevant during a pandemic or epidemic.

Methods: The PaSS was administered in N = 2760 German participants. Exploratory factor analysis was used to extract factors. The factor structure obtained in the German sample was examined in N = 1021 Austrian participants using confirmatory factor analysis. $\chi^{2}$, RMSEA, SRMR, CFI, TLI were assessed as global goodness of fit indices for two models (Model 1: nine-factor model; Model 2: nine-factor model combined with a second-order general factor). We additionally assessed factor loadings, communalities, factor reliability, discriminant validity as local fit indices. Internal consistency, item discrimination, and item difficulty were assessed as additional test quality criteria.

Results: The results of the exploratory factor analysis suggested a nine-factor solution with factor loadings accounting for $50.4 \%$ of the total variance (Factor 1 'Problems with Childcare', Factor 2 'Work-related Problems', Factor 3 'Restricted Face-to-Face Contact', Factor 4 'Burden of Infection ', Factor 5 'Crisis Management and Communication', Factor 6 'Difficult Housing Condition', Factor 7 'Fear of Infection', Factor 8 'Restricted Access to Resources', Factor 9 'Restricted Activity'). The confirmatory factor analysis showed a sufficient global fit for both tested models (Model 1: $\chi^{2}(369, N=1021)=$ $1443.28, p<.001, \mathrm{RMSEA}=.053, \mathrm{SRMR}=.055, \mathrm{CFI}=.919, \mathrm{TLI}=.904 ;$ Model $2: \chi^{2}(396, N=1021)=1948.51, p<.001, \mathrm{RMSEA}=.062, \mathrm{SRMR}=.074, \mathrm{CFI}$ $=.883, \mathrm{TLI}=.871)$. The results of the chi-square difference test indicated a significantly better model-fit of Model 1 compared to Model $2\left(\Delta \chi^{2}(27, N=\right.$ $1021)=505.23, p<.001)$. Local goodness of fit indices were comparable for both tested models. We found good factor reliabilities for all factors and moderate to large factor loadings of the items as indicators. In Model 2, four first-order factors showed small factor loadings on the second-order general factor.

Conclusion: The Pandemic Stressor Scale showed sufficient factorial validity for the nine measured domains of stressors during the current COVID-19 pandemic.

\section{Introduction}

The COVID-19 pandemic has affected the global population. Lockdown measures such as working from home, physical distancing, reduced social contact, and mask-wearing were implemented to reduce the spread of COVID-19. These measures are related to multiple stressors, including organizing home office, and combining childcare with working from home [1, 2]. Reduced leisure possibilities can be an additional burden, which have been shown to be associated with symptoms of depression and anxiety $[3,4]$. The chronic reduction of face-to-face contact is related to increased levels of loneliness, distress, and anxiety [5]. Furthermore, the preventive measures have adversely impacted the economy [6]; many people face financial difficulties and are strained by financial worries [7].

These multiple stressors have been associated with increased levels of mental health problems. Studies conducted during the early phase of the pandemic found heightened levels of psychological distress [e.g. 5,8,9], depression [e.g. 5,10,11], anxiety [e.g. 12,13], and posttraumatic stress disorder [PTSD; 14] in the general population.

To better understand the mental health burden of the COVID-19 pandemic and to identify high-risk groups, a validated measure of the pandemic-specific stressors is needed to examine which stressors are most burdensome and how these stressors impact wellbeing and mental health.

During the COVID-19 pandemic, several measures have been developed to capture distress or relevant clinical symptoms such as distress, anxiety, fear, sleeping problems, and posttraumatic stress symptoms related to the COVID-19 pandemic. These include the 'COVID Stress Scales' [CSS; 15], the 'Fear of COVID-19 Scale' [FCV-19S; 16], the 'Coronavirus Anxiety Scale' [CAS; 17], and the 'COVID-19 Burnout Scale' [COVID-19 BS; ,18]. The 'COVID-19-PTSD' [19], 'COVID-19 Traumatic Stress Scale' [20], and the 'CoViD-19 Peritraumatic Distress Index' [CPDI; 21] were developed to assess symptoms of PTSD in the context of the current pandemic. These measures assess the perceived global level of distress during the COVID-19 pandemic. However, by focusing on distress on a global level, these questionnaires can not distinguish between the burden of different stressors.

Few measures have been developed to assess different pandemic stressors. The 'Stressors of COVID-19 Scale' [22] is a 19-item questionnaire measuring the perceived stressfulness of COVID-19 stressors on 5-point scales. The measure covers four domains, including Disease-related stressors, e. g. 'I am worried that I will be infected'; Information-related stressors, e. g. 'I heard some negative news about COVID-19'; Public health measure-related stressors, e. g. 'Academic schedule was disrupted'; and Environmental stressors, e. g. 'I am separated and alienated from my classmates and friends'. The measure was developed in a study of Chinese college students. A first validation study exists only for the Chinese questionnaire, with Cronbach's a of .94 for the total score [22]. The questionnaire does not cover the domains of home-related stressors (e.g., restricted housing condition, conflicts at home, lack of childcare) and work-related changes.

Kujawa et al. [23] developed the 'Pandemic Stress Questionnaire' (PSQ) to assess pandemic-related stressors and severity of distress on 5-point scales. The 25 items are grouped into six subscales (General life disruption, Interpersonal, Financial, Educational/professional goals, Health-self, and Healthothers). In a US sample, good internal consistencies of the total severity score $(a=.79)$ and convergent validity with the Perceived Stress Scale [24]have been reported; no further data about the validation of the measure could be identified. The questionnaire does not consider COVID-19 infection-related stressors (e.g., fear of contracting COVID-19), and stressors related to the government's response (e.g., crisis communication). 
The 'COVID-19 Stressors Scale' [25] is a 23-item questionnaire that assesses exposure to COVID-19 specific stressors and severity of burden on 5-point scales within the past week on three subscales ('Infection-related stressors', 'Daily activity-related stressors', and 'Financial/resource-related stressors'). However, the scale was evaluated by using an Exploratory Factor Analysis (EFA) that yielded a one-factor solution accounting for only $21.76 \%$ of the variance [26]. While internal consistency (Cronbach's a $=.96$ ) was high, factor loadings were moderate to high (item-total correlations .61 - .86), and item discrimination was moderate to good $\left(r_{i t}=.46-.74\right)$. The questionnaire showed convergent validity with the Perceived Stress Scale [24] and Generalized Anxiety Disorder Scale-7 [GAD-7; 27]. A further shortcoming of the questionnaire might be seen in the fact that the measure assesses restricted social contact by only one item, although restricted social contact seems to be a key stressor during the COVID-19 pandemic, which has been reported as particularly burdensome [28-30].

Another measure assessing exposure to pandemic-specific stressors is the 21-item 'COVID-19 Stress Scale' [CSS; 31]. The CSS measures the frequency of feelings and thoughts about different stressors on 5-point scales ('Almost never' to 'All the time'). An EFA has been conducted based on the data of a convenience sample in India, which revealed five factors that explained $55.27 \%$ of the variance (Vexation with others, Immediate concerns, Routine disruption, Uncertainty about the future, and Systematic stressors; Ahuja, 2021). However, the EFA has not been confirmed with confirmatory factor analysis (CFA) in a different sample. Internal consistency for the total score was high $(a=.90)$ and ranged between $.69-.85$ for the subscales. The measure does not capture home-related stressors, e.g., conflicts at home or problems with childcare.

The 'COVID-19 Stressors Score' has been developed for a study by Ettman et al. [32] to assess the cumulative exposure to 13 pandemic-specific stressors. To our knowledge, no psychometric evaluation has been conducted. Furthermore, several additional unnamed items have been used to acquire information about pandemic-specific stressors [e.g., 33-35] that have not been psychometrically tested.

For all questionnaires listed above, limited or no evidence on their factorial validity could be identified. Psychometric information most often concerned internal consistency assessed with Cronbach's a [e.g., 22]. Two studies performed an EFA [26, 31], but no CFA has been conducted on any of the identified measures to confirm the dimensional structure. Overall, no measure has been psychometrically evaluated in more than one study. Many measures leave out important domains of stressors, such as home-related stressors; no measure addressed difficult housing conditions. To assess the multiple stressors of a pandemic or epidemic, the psychometric examination of such a measure is needed. Therefore, this study aimed to assess the factorial validity and reliability of the Pandemic Stressor Scale, a newly developed measure of assessing specific stressors during a pandemic or epidemic.

\section{Methods Initial Scale Development}

We developed the Pandemic Stressor Scale (PaSS) to measure the severity of the burden of different stressors relevant during a pandemic or epidemic. After reviewing the previous literature on pandemic-related stressors, a clinical psychologist in trauma and stress researcher (first author) constructed an item set, which was reviewed, reduced and revised by an international consortium of trauma and stress experts that were members of the European Society of Traumatic Stress Studies (ESTSS). The final questionnaire contained 43 stressors related to a COVID-19 infection (e.g., fear of contracting COVID-19); governmental response and availability of resources (e.g., poor information from the government); staying at home (e.g., difficulties with combining work with childcare); public-life restrictions (e.g., restricted leisure activity); face-to-face Contact restrictions (e.g., restricted personal contact to loved ones); or work (e.g., financial and job loss).

We used the following instruction to assess the severity of the burden of the 48 stressors: 'Please indicate how much the following things have burdened you due to the coronavirus pandemic within the last month.' The items were rated on five-point scales ranging from 0 to 4 ( 0 = 'Not at all burdened'; 1 = 'Somewhat burdened'; 2 = 'Moderately burdened'; 3 = 'Strongly burdened', 4 = 'Does not apply to me'). Higher scores indicate a greater burden.

\section{Study design}

This study is a secondary cross-sectional analysis that used data from a longitudinal cohort study to investigate relationships between stressors and symptoms of psychological adjustment disorder during the COVID-19 pandemic [36]. Data reported in this manuscript were drawn from two study sites of the more extensive study (Germany and Austria). All participants provided informed consent to participate in the study. The study was registered in a study registry before starting the study (doi: 10.17605/OSF.IO/8XHYG).

\section{Study Participants}

Participants were drawn from the general population that (1) were at least 18 years of age and (2) willing to participate in the study.

\section{Sample and Procedure}




\section{Measures}

The Pandemic Stressor Scale (PaSS) is a self-report questionnaire to assess the severity of the burden for different stressors relevant during a pandemic or epidemic. The items are rated on four-point scales ranging from 0 to 4 ( 0 = 'Not at all burdened'; 1 = 'Somewhat burdened'; 2 = 'Moderately burdened'; 3 = 'Strongly burdened', 4 = 'Does not apply to me'). Higher scores indicate a greater burden. Completion of the questionnaire takes about 10 minutes. The initial questionnaire contained 48 items. Sociodemographic characteristics were assessed by self-constructed items.

\section{Data Analysis}

First, we conducted an EFA to initially investigate the dimensional structure of the PaSS in a German sample. Afterwards, a CFA was conducted to examine whether the factorial structure obtained by EFA could be replicated in another sample.

\section{Study 1: Exploratory Factor Analysis}

To examine the factor structure of the PaSS, we conducted an exploratory factor analysis (EFA). The initial EFA included 43 items measuring different pandemic stressors in a German sample of $n=2760$ participants. Missing data per variable ranged from $0(0.00 \%)$ to $3(0.11 \%)$. Missing values were imputed by using the Expectation-Maximization algorithm of SPSS 27 . Before conducting an EFA, the category $4=$ 'Does not apply to me' category was recoded to $0=$ 'Not at all burdened'. The EFA was done following current recommendations [37]. Maximum Likelihood was used as the extraction method, as recommended when measures will be used with other datasets in the future [38]. An oblimin rotation with Kaiser normalization was applied. We removed items with communalities of less than .20. Afterward, the EFA was re-run.

We determined the optimal number of factors using the following criteria: (1) Kaiser's criterion (eigenvalue > 1); (2) a solution of a maximum number of factors with at least two items with a loading greater than .40 and a low cross-loading. Items with factor loadings $<.40$ and/or cross-loadings $>75 \%$ were removed, starting with the one with the lowest absolute maximum loading on all the factors. The analyses were conducted in SPSS 22.0 .

\section{Study 2: Confirmatory Factor Analysis}

To confirm the factorial structure of the PaSS identified in the first sample, a CFA was conducted in a second sample of $N=1021$ participants. We imputed missing data using the Expectation Maximization procedure. Data analyses were performed using SPSS 27 , and SPSS AMOS 26 Graphics. We tested two models based on the results of the EFA. Model 1 consisted of the indicators that represented the items of the questionnaire and nine firstorder factors. Correlations between factors were expected and allowed. Model 2 consisted of the same indicators and first-order factors as Model 1 and was extended by a second-order general factor on which all first-order factors loaded.

The Maximum Likelihood (ML) estimation method was used for the CFA. The skew- $\left(\mathrm{Y}_{1}\right)$ and kurtosis index $\left(\mathrm{Y}_{2}\right)$ were used to test for normal distribution of the indicators as a prerequisite for ML estimations; $\left|\gamma_{1}\right| \geq 3.0$ and $\left|\gamma_{2}\right| \geq 10.0$ were considered as problematic [39, p. 76-77].

\section{Global Goodness of Fit.}

Indices and cut-offs to examine global model-fit were selected based on recommendations proposed by Schermelleh-Engel [40]: $\chi^{2}$ statistics and normed $\chi^{2}\left(\chi^{2} / \mathrm{df} ; \chi^{2} / \mathrm{df} \leq 3\right.$ rated as acceptable and $\chi^{2} / \mathrm{df} \leq 2$ as good), Root Mean Square Error of Approximation (RMSEA $\leq .08$ rated as acceptable and RMSEA $\leq .05$ rated as good), and Standardized Root Mean Residual (SRMR $\leq .10$ rated as acceptable and $\leq .05$ rated as good).

The Tucker Lewis Index $(\mathrm{TLI})$ and Comparative Fit Index $(\mathrm{CFI})>.90$ were rated as acceptable, taking the large sample size and model complexity into account [41].

\section{Local Goodness of Fit.}

Local goodness of fit indices were assessed to examine specific parts of the tested models. On the level of indicator, factor loadings $(\lambda \geq .50$ rated as moderate, $\lambda \geq .70$ rated as large; [41]) and their statistical significance by Critical Ratio (C.R. $\geq|1.96|$ ) were examined. Factor communalities were also assessed $\left(\lambda^{2} \geq .50\right.$ rated as acceptable; [41]).

On the level of the factor, factor reliabilities (FR > .60; [42]) were examined. To test evaluate the discriminant validity of the factors, the Fornell-Larcker criterion was used [43]. The Fornell-Larcker criterion compares the Average Variance Extracted (AVE) with the coefficient of determination ( $\left.R^{2}\right)$ between two factors. If $A V E>R^{2}$, the two factors are considered discriminant from each other. 


\section{Additional test quality criteria.}

Internal consistency of the factors was estimated by Cronbach's a. The number of indicators per factor ratings was based on the recommendations of Ponterotto and Ruckdeschel [44]. Item difficulty coefficients were calculated by dividing the mean of the items by the maximum item score [assumed as good if $.20 \leq \mathrm{P} \leq .80 ;$ [45]). To assess item discrimination, corrected item-total correlations were computed $\left(r_{i t} \geq .30\right.$ rated as acceptable and $r_{i t} \geq .50$ as good; [46], p. 52).

\section{Model comparison.}

To compare Model 1 and Model 2, a chi-square difference test was conducted $\left(\Delta \chi^{2}=\chi^{2}\right.$ Model $2-\chi^{2}$ Model 1 and $\Delta d f=d f$ Model $2-d f$ Model 1 ; [39], $p$. 281). A conservative significance level of $a=.01$ was chosen because chi-square tests tend to be over-sensitive in large samples [41].

Results

Study 1

\section{Sample Characteristics}

The study included $N=2760$ adult participants from the general German population (Table 1). Seven out of ten participants were female, three out of ten were male. Participants' age ranged from 18 to 87 years. The education level was high on average. About one out of a hundred participants had been infected with the coronavirus. Seven out of hundred reported a corona infection of loved ones, and one-third of the participants reported knowing someone personally who has been infected. Two out of ten classified themselves as being at risk for severe or life-threatening symptoms of the coronavirus disease.

\section{Exploratory Factor Analysis}

The majority of the items were approximately normally distributed, although some items showed a negative skew (Table 2). The item set of 43 items used in the initial EFA was further reduced, based on their psychometric properties (see methods section). The communalities of the initial EFA solution were $>.20$ for all items, indicating that all items could be retained. Five items with communalities less than 0.2 were removed (Violent assaults at home; Restricted religious or spiritual activities; Increased workload; Restricted work travel; Working in close contact with people who could be infected). Four items with factor loadings < .40 were removed (Working from home (home office); Being rejected by others because of own coronavirus infection; Unable to attend the funeral; Restricted physical activity). Four items with cross-loadings $>75 \%$ were removed (Loss of daily structure; Being at home most of the time; Having infected others with the coronavirus; Unable to visit loved ones in a critical situation).

The final item set included 30 items. A nine-factor solution showed the best fit with the data and a sufficient interpretability of the factors. The factor solution was confirmed by visual examination of the scree plot. No additional factor exceeded the threshold of an Eigenvalue of 1.0. Each item had a salient loading of $>.40$ on the respective factor. No item of the rotated factor matrix cross-loaded more than $75 \%$ on another factor.

The factor loadings of the 30 items ranged between .409 and .949 (Table 3), suggesting meaningful and significant factor loadings [47]. The factors were named as follows: 'Restricted Face-to-Face Contact', 'Problems with childcare', 'Work-related problems', 'Fear of infection', 'Burden of infection', 'Restricted activity', 'Crisis management and communication', 'Restricted access to resources', and 'Difficult housing condition' (Appendix 1).

\section{Study 2}

\section{Sample Characteristics}

The study included a sample of $N=1021$ adults from the general population of Austria (Table 1). The sociodemographic population characteristics were similar to those of the German sample. About two-thirds were female; one-third were male. Participants' age ranged between 18 and 80 years. The sample had an overall high education level. About one out of a hundred participants had been infected with the coronavirus, seven out of a hundred reported a corona infection of loved ones, and forty out of a hundred knew someone personally who has been infected.

\section{Confirmatory Factor Analysis}

All indicators were approximately normally distributed (skew index $\left|\gamma_{1}\right|<3.0$ and kurtosis index $\left|\gamma_{2}\right|<10.0 ;$ Table 2; Kline, 2015, p. 76-77).

\section{Model 1.}




\section{Global Goodness of Fit.}

The $\chi^{2}$ statistics showed a statistically significant difference between the model and the observed data $\left(\chi^{2}(369, N=1021)=1443.28, p<.001\right.$, normed $\chi^{2}=3.91$, Table 4). Both the RMSEA (RMSA $\left.=.053, p=.026,90 \% \mathrm{Cl}=.051, .056\right)$ and the SRMR $(.055)$ showed an acceptable fit. The CFI (.919) and the TLI (.904) indicated an acceptable fit of the model.

\section{Local Goodness of Fit.}

All factor loadings were moderate $(\lambda \geq .50)$ to large $(\lambda \geq .70$; Table 5$)$ and significant (C.R. $\geq|1.96|)$. 16 indicators showed acceptable communalities $\lambda^{2} \geq$.50. All factors showed discriminant validity, except for 'Restricted Activity', which was not discriminant from 'Restricted Face-toFace Contact'. Factor reliability was considered as good with FR $>.60$ for all factors.

\section{Additional test quality criteria.}

Internal consistency was excellent for 'Problems with Childcare' $(\alpha=.94)$, 'Work-related Problems' $(\alpha=.86)$ and 'Restricted Face-to-Face Contact' $(\alpha=$ .85), moderate for 'Burden of Infection' ( $a=.77$ ), 'Crisis Management and Communication' ( $a=.77$ ) and 'Difficult Housing Condition' ( $a=.78$ ), and acceptable for 'Fear of Infection' ( $a=.74)$ and 'Restricted Activity' $(a=.72)$. The 'Restricted Access to Resources' factor showed low internal consistency $(a=.63 ;$ Table 6$)$. Item difficulty indices showed that twelve of the indicators were difficult $(P<.20)$. Three factors showed average difficulty coefficients of $P<.20$ ('Problems with Childcare', 'Work-related Problems' and 'Difficult Housing Condition'). Item discrimination indices were evaluated as good (24 items $r_{i t}>$.50) or acceptable (6 items $r_{i t}>$.30). The average item discrimination indices for the factors were good for eight of the nine factors and acceptable for 'Restricted Access to Resources' (Table 7).

\section{Model 2.}

\section{Global Goodness of Fit.}

The $\chi^{2}$ statistics showed a statistically significant difference between the theoretical model and the observed data $\left(\chi^{2}(396, N=1021)=1948.51, p<\right.$ .001 , normed $\chi^{2}=4.92$; Table 4). The RMSEA $(.062, p<.001,90 \% \mathrm{Cl}=.059, .065)$ and the SRMR (.074) indicated an acceptable model fit. However, the CFI (.883) and TLI (.871) showed an insufficient model fit.

\section{Local Goodness of Fit.}

Factor loadings of the indicators were all moderate to large (Table 5). Four factor loadings of the first-order factors on the second-order general factor were small: 'Problems with Childcare' $(\lambda=.24)$, 'Work-related Problems' $(\lambda=.41)$, 'Burden of Infection' $(\lambda=.42)$ and 'Difficult Housing Condition' $(\lambda=.49)$. Three factors showed moderate factor loadings on 'Pandemic Stressors': 'Crisis Management and Communication' $(\lambda=.56)$, 'Fear of infection' ( $\lambda=.59)$ and 'Restricted Access to Resources' $(\lambda=.60)$. 'Restricted Face-to-Face Contact' $(\lambda=.79)$ and 'Restricted Activity' $(\lambda=.72)$ showed a large factor loading on the second-order general factor (Table 5). All factor loadings were significant (C.R. $\geq|1.96|$ ). Acceptable communalities $\left(\lambda^{2} \geq .50\right)$ were found for 17 indicators. Factor reliabilities were similar to those found in Model 1 and were all considered good $(F R>.60)$. The second-order general factor showed a high factor reliability of $\mathrm{FR}=.97$ (Table 6$)$.

\section{Additional test quality criteria.}

The second-order general factor showed a moderate internal consistency ( $a=.88$; Table 7$)$. Average item difficulty for this factor was evaluated as good $(P=.30)$ but was close to the lower bound of the interval $(.20 \leq P \leq .80)$, indicating an overall high difficulty. For the internal consistencies and item difficulties of the first-order factors, please see the results section for Model 1. Item discrimination indices concerning the second-order general factor were mostly acceptable.

\section{Model comparison.}

The chi-square difference test comparing Model 1 and Model 2 showed a significant difference of the models in their fit to the data $\left(\Delta \chi^{2}(27, N=1021)\right.$ $=505.23, p<.001)$. These results mean that the less complex model (Model 1) fits better to the observed data than the more complex one (Model 2).

\section{Discussion}

Around the world, the COVID-19 pandemic burdens the lives of people. As the duration of the pandemic increases, so does the importance of measuring the adverse effects of stressors on people's mental health and wellbeing with valid measures. This research aimed to examine the factorial validity and reliability of a new scale, the Pandemic Stressor Scale (PaSS), that aims to assess the different stressors relevant during a pandemic or epidemic. First, 
an EFA was conducted in a German sample of participants. Second, the dimensional structure identified in the first analysis was examined using CFA in the second sample of Austrian participants to examine its replicability. Global and local goodness of fit indices and additional test quality criteria were evaluated in two models: A nine-factor model (Model 1) and a nine-factor model with a second-order general factor (Model 2 ).

\section{Exploratory Factor Analysis}

A nine-factor solution of the PaSS, including 30 items, showed the best fit with the data and sufficient interpretability of the factors. The factor loadings of the 30 items ranged between .409 and .949, suggesting meaningful and practically significant factor loadings [47]. The identified factors were 'Restricted Face-to-Face Contact', 'Problems with Childcare', 'Work-Related Problems', 'Fear of Infection', 'Burden of Infection', 'Restricted Activity', 'Crisis Management and Communication', 'Restricted Access to Resources', and 'Difficult Housing Condition'. While five of the nine factors consistently showed low factor loadings on the other factors, four factors showed factors loadings greater than .40 on one additional factor. Three items of the factor 'Restricted Face-to-Face Contact' ('Restricted face-to-face contact with others', 'Social isolation', 'Restricted physical closeness to loved ones') showed factor loading greater than .40 on the 'Restricted activity' factor. The factor 'Difficult housing conditions' included one item ('No place of retreat') that showed loadings greater than .40 on the 'Problems with Childcare' factor; one item of the 'Fear of Infection' factor ('Fear of getting infected with the coronavirus') loaded greater than .40 on the 'Burden of infection' factor. Finally, two items of the 'Restricted Face-to-Face Contact' factor ('Restricted leisure activity', 'Restricted everyday activity') loaded greater than .40 on the 'Restricted Activity' factor. High cross-loading may indicate that the indicators measure both constructs. However, all items showed lower cross-loadings than 75\%, as recommended [47].

All existing questionnaires on pandemic-related stressors were shorter, including between 13 and 25 [e.g., 22,23,35]. These questionnaires might only partly cover pandemic-related stressor domains, such as home-related stressors (e.g., restricted housing conditions, conflicts at home, lack of childcare), or work-related changes. By assessing nine stressor domains with 30 stressors, the PaSS might allow capturing a broader range of stressor domains.

\section{Confirmatory Factor Analysis}

\section{Global Fit.}

The obtained dimensional structure identified in the EFA could be replicated by Model 1. The SRMR, RMSEA global fit indices showed acceptable fit, as well as the TLI and CFI. The $\chi^{2}$ statistics of both models indicated significant differences between the theoretical model and the data; however, this measure tends to be overly sensitive in large samples [41]. The global fit of Model 2 was below the threshold we defined for acceptable fit. The comparison of the two models via $\chi^{2}$ difference test showed that Model 1 fitted better than Model 2. Consequently, a second-order global factor on which all first-order factors load seems not to be reflected in the data.

\section{Local Fit.}

On the level of the indicators, factor loadings of the items as indicators on the first-order factors were moderate to large. However, in Model 2, four of the nine first-order factors had small factor loadings on the second-order general factor. Only the factors 'Restricted Face-to-Face Contact', 'Crisis Management and Communication', 'Fear of Infection', 'Restricted Access to Resources' and 'Restricted Activity' showed large or moderate factor loadings on a general second-order factor. This result indicates, in line with the significant result of the chi-square difference test, that the computation of a total score might not be reasonable.

Future studies might test models which include more than one second-order factor. While most of the indicators showed acceptable commonalities, some showed low communalities, indicating that a part of the indicator variance remained unexplained by the respective factor.

On the level of the factors, all factors showed acceptable factor reliabilities, including the second-order general factor. The indicators of each factor shared a sufficient amount of variance within this factor, which indicates that they likely measure a similar construct. All factors except the factor 'Restricted Access to Resources' discriminated well from each other.

\section{Item Difficulty.}

Twelve items had high difficulties, indicating that the respective stressors measured were not considered a severe burden by many participants. This is reflected in the difficulty index of the second-order general factor which is acceptable but close to the lower bound $(P=.30)$. The high item difficulties in some items resulted in reduced item variance. Most calculations of a CFA are based on variance-covariance matrices that are affected by reduced item variance, resulting in lower global and local fit indices. The restricted item variance in some of the items might have lowered global fit. However, global fit was acceptable in all assessed indices in Model 1. Items with the lowest difficulties might be removed from the questionnaire to increase item variance.

However, while some stressors were not perceived as stressful, it has to be considered that we assessed the data during the summer and autumn time of the first year of the pandemic. For this time period, the burden was reduced, as the lockdown measures were relaxed in both countries and people had

Page $7 / 18$ 
the opportunity to spend time outside. Future studies need to reassess the items and their difficulties to a later timepoint of the pandemic, in which the burden of the stressors could be increased, e.g., during a subsequent lockdown period.

\section{Item Discrimination and Internal Consistency.}

Most item discrimination indices were considered acceptable to good, except for three indicators that did not discriminate well between high and low scores of the second-order general factor in Model 2. These results indicate that the items discriminated well between high and low scores of the firstorder factor, the discriminated less well concerning the second-order general factor. Internal consistencies were acceptable for all factors except for 'Restricted Access to Resources'. In Model 2, the second-order general factor showed a moderate internal consistency ( $a=.88$ ).

\section{Model Comparison.}

The chi-square difference test showed a better model-fit of Model 1 compared to Model 2. The only difference between the models is the second-order general factor called 'Pandemic Stressors'. Four of the first-order factors showed small factor loadings on the global second-order factor and less good item discrimination indices for the global factor than those concerning the first-order factors. These results indicate a less well fit of the nine-factor model that includes a second-order general factor, which is consistent with the results found on the level of the local fit indices.

\section{Strength and Limitations}

A strength of this study is the use of sufficiently sized samples and the combined use of EFA and CFA in two different large samples to replicate the results obtained in EFA. A limitation of the study is that we used a non-probability sample that was not representative of the general populations of Germany and Austria concerning gender, income, and education. Future studies need to examine the psychometric properties of the PaSS among representative samples. Furthermore, a comprehensive validity testing needs to include convergent and discriminant validity. As the focus of this study was to assess the factorial validity of the PaSS, we did not examine the convergent and discriminant validity of the measure. The measure's convergent and discriminant validity with other stressor measures need to be examined in future studies. Finally, the psychometric properties of the measure should be examined in the general populations of other countries than Germany and Austria.

\section{Conclusion}

Overall, the findings of both analyses empirically support the factorial validity and reliability of the Pandemic Stressor Scale. Further studies might need to examine additional psychometric aspects of the measure.

\section{Declarations}

\section{Ethics approval and consent to participate}

The larger study was approved by the local ethic commitee of the respective study site (Germany: Local Psychological Ethics Committee at the Centre for Psychosocial Medicine, LPEK-0149; Austria: Ethics Committee of the University of Vienna, Reference Number: 00554). All participants provided informed consent before participating. The longitudinal cohort study was registered in a study registry (https://doi.org/10.17605/OSF.IO/8XHYG).

All methods were performed in accordance with the relevant guidelines and regulations.

\section{Consent for publication}

"Not applicable"

\section{Availability of data and materials}

Data supporting the findings of this study is available upon reasonable request from the first author.

\section{Competing interests}

The authors declare to have no interests that affect the data analysis, reporting of results, and interpretation.

\section{Funding}

This study received no funding. 


\section{Authors' contributions}

AL designed and coordinated the study, drafted the manuscript, and carried out the EFA; RK carried out the CFA and contributed to the writing of the manuscript; MB contributed to the recruitment. IZ, BL, MB, and IS reviewed the manuscript and approved the final manuscript.

\section{Acknowledgments}

We greatly thank the study team, in particular, Laura Kenntemich for the data management, and Sven Buth and Eike Neumann-Runde for his technical support in the setup of the survey. The authors thank the ESTSS COVID-19 study consortium (please see https://doi.org/10.17605/OSF.IO/8XHYG) for reviewing the PaSS items.

\section{References}

1. Palumbo R. Let me go to the office! An investigation into the side effects of working from home on work-life balance. Int J Public Sect Manag. 2020;33: 771-790. doi:10.1108/IJPSM-06-2020-0150

2. Rubin O, Nikolaeva A, Nello-Deakin S, Brömmelstroet MT. What can we learn from the COVID-19 pandemic about how people experience working from home and commuting? 2020 [cited 19 May 2021]. doi:10.13140/RG.2.2.34785.74080

3. Faulkner J, O'Brien WJ, McGrane B, Wadsworth D, Batten J, Askew CD, et al. Physical activity, mental health and well-being of adults during initial COVID-19 containment strategies: A multi-country cross-sectional analysis. J Sci Med Sport. 2021;24: 320-326. doi:10.1016/j.jsams.2020.11.016

4. Stanton R, To QG, Khalesi S, Williams SL, Alley SJ, Thwaite TL, et al. Depression, Anxiety and Stress during COVID-19: Associations with changes in physical activity, sleep, tobacco and alcohol use in Australian adults. Int J Environ Res Public Health. 2020;17: 4065. doi:10.3390/ijerph17114065

5. Bäuerle A, Teufel M, Musche V, Weismüller B, Kohler H, Hetkamp M, et al. Increased generalized anxiety, depression and distress during the COVID19 pandemic: a cross-sectional study in Germany. J Public Health. 2020;42: 672-678. doi:10.1093/pubmed/fdaa106

6. Ali M, Alam N, Rizvi SAR. Coronavirus (COVID-19) - An epidemic or pandemic for financial markets. J Behav Exp Finance. 2020;27: 100341. doi:10.1016/j.jbef.2020.100341

7. Wilson JM, Lee J, Fitzgerald HN, Oosterhoff B, Sevi B, Shook NJ. Job insecurity and financial concern during the COVID-19 pandemic are associated with worse mental health. J Occup Environ Med. 2020;62: 686-691. doi:10.1097/JOM.0000000000001962

8. Geirdal A $\varnothing$, Ruffolo M, Leung J, Thygesen H, Price D, Bonsaksen T, et al. Mental health, quality of life, wellbeing, loneliness and use of social media in a time of social distancing during the COVID-19 outbreak. A cross-country comparative study. J Ment Health. 2021; 1-8. doi:10.1080/09638237.2021.1875413

9. Wu T, Jia X, Shi H, Niu J, Yin X, Xie J, et al. Prevalence of mental health problems during the COVID-19 pandemic: A systematic review and metaanalysis. J Affect Disord. 2021;281: 91-98. doi:10.1016/j.jad.2020.11.117

10. Bueno-Notivol J, Gracia-García P, Olaya B, Lasheras I, López-Antón R, Santabárbara J. Prevalence of depression during the CoVID-19 outbreak: A meta-analysis of community-based studies. Int J Clin Health Psychol. 2021;21: 100196. doi:10.1016/j.ijchp.2020.07.007

11. Pieh C, O’Rourke T, Budimir S, Probst T. Relationship quality and mental health during COVID-19 lockdown. Montazeri A, editor. PLOS ONE. 2020;15: e0238906. doi:10.1371/journal.pone.0238906

12. Santabárbara J, Lasheras I, Lipnicki DM, Bueno-Notivol J, Pérez-Moreno M, López-Antón R, et al. Prevalence of anxiety in the COVID-19 pandemic: An updated meta-analysis of community-based studies. Prog Neuropsychopharmacol Biol Psychiatry. 2021;109: 110207. doi:10.1016/j.pnpbp.2020.110207

13. Shah SMA, Mohammad D, Qureshi MFH, Abbas MZ, Aleem S. Prevalence, psychological responses and associated correlates of depression, anxiety and stress in a global population, during the Coronavirus Disease (COVID-19) pandemic. Community Ment Health J. 2021;57: 101-110. doi:10.1007/s10597-020-00728-y

14. Kar N, Kar B, Kar S. Stress and coping during COVID-19 pandemic: Result of an online survey. Psychiatry Res. 2021;295: 113598. doi:10.1016/j.psychres.2020.113598

15. Taylor S, Landry CA, Paluszek MM, Fergus TA, McKay D, Asmundson GJG. Development and initial validation of the COVID Stress Scales. J Anxiety Disord. 2020;72: 102232. doi:10.1016/j.janxdis.2020.102232

16. Ahorsu DK, Lin C-Y, Imani V, Saffari M, Griffiths MD, Pakpour AH. The Fear of COVID-19 Scale: Development and initial validation. Int J Ment Health Addict. 2020 [cited 17 May 2021]. doi:10.1007/s11469-020-00270-8

17. Lee SA. Coronavirus Anxiety Scale: A brief mental health screener for COVID-19 related anxiety. Death Stud. 2020;44: 393-401. doi:https://doi.org/10.1080/07481187.2020.1748481

18. Yıldırım M, Solmaz F. COVID-19 burnout, COVID-19 stress and resilience: Initial psychometric properties of COVID-19 Burnout Scale. Death Stud. 2020; 1 -9. doi:10.1080/07481187.2020.1818885

19. Forte G, Favieri F, Tambelli R, Casagrande M. COVID-19 Pandemic in the Italian Population: Validation of a post-traumatic stress disorder questionnaire and prevalence of PTSD symptomatology. Int J Environ Res Public Health. 2020;17: 4151. doi:10.3390/ijerph17114151 
20. Kira IA, Shuwiekh HAM, Rice KG, Ashby JS, Elwakeel SA, Sous MSF, et al. Measuring COVID-19 as traumatic stress: Initial psychometrics and validation. J Loss Trauma. 2021;26: 220-237. doi:10.1080/15325024.2020.1790160

21. Qiu J, Shen B, Zhao M, Wang Z, Xie B, Xu Y. A nationwide survey of psychological distress among Chinese people in the COVID-19 epidemic: implications and policy recommendations. Gen Psychiatry. 2020;33: e100213. doi:10.1136/gpsych-2020-100213

22. Ye B, Wu D, Im H, Liu M, Wang X, Yang Q. Stressors of COVID-19 and stress consequences: The mediating role of rumination and the moderating role of psychological support. Child Youth Serv Rev. 2020;118: 105466. doi:10.1016/j.childyouth.2020.105466

23. Kujawa A, Green H, Compas BE, Dickey L, Pegg S. Exposure to COVID-19 pandemic stress: Associations with depression and anxiety in emerging adults in the United States. Depress Anxiety. 2020;37: 1280-1288. doi:10.1002/da.23109

24. Cohen S, Kamarck T, Mermelstein R. A Global Measure of Perceived Stress. J Health Soc Behav. 1983;24: 385. doi:10.2307/2136404

25. Park CL, Russell BS, Fendrich M, Finkelstein-Fox L, Hutchison M, Becker J. Americans' COVID-19 Stress, coping, and adherence to CDC Guidelines. J Gen Intern Med. 2020;35: 2296-2303. doi:10.1007/s11606-020-05898-9

26. Tambling RR, Russell BS, Park CL, Fendrich M, Hutchinson M, Horton AL, et al. Measuring cumulative stressfulness: Psychometric properties of the COVID-19 Stressors Scale. Health Educ Behav. 2021;48: 20-28. doi:10.1177/1090198120979912

27. Spitzer RL, Kroenke K, Williams JBW, Löwe B. A brief measure for assessing Generalized Anxiety Disorder: The GAD-7. Arch Intern Med. 2006;166: 1092-1097. doi:10.1001/archinte.166.10.1092

28. Bu F, Steptoe A, Fancourt D. Who is lonely in lockdown? Cross-cohort analyses of predictors of loneliness before and during the COVID-19 pandemic. Public Health. 2020;186: 31-34. doi:10.1016/j.puhe.2020.06.036

29. Groarke JM, Berry E, Graham-Wisener L, McKenna-Plumley PE, McGlinchey E, Armour C. Loneliness in the UK during the COVID-19 pandemic: Crosssectional results from the COVID-19 Psychological Wellbeing Study. Murakami M, editor. PLOS ONE. 2020;15: e0239698. doi:10.1371/journal.pone.0239698

30. Li, Wang. Prevalence and predictors of general psychiatric disorders and loneliness during COVID-19 in the United Kingdom. Psychiatry Res. 2020;291: 113267. doi:10.1016/j.psychres.2020.113267

31. Ahuja KK. Scanning the VIRUS: A study of dimensions of stress and coping with COVID-19. Curr Psychol. 2021; 1-11.

32. Ettman CK, Abdalla SM, Cohen GH, Sampson L, Vivier PM, Galea S. Prevalence of depression symptoms in US adults before and during the COVID19 pandemic. JAMA Netw Open. 2020;3: e2019686. doi:10.1001/jamanetworkopen.2020.19686

33. Islam SMD-U, Bodrud-Doza Md, Khan RM, Haque MdA, Mamun MA. Exploring COVID-19 stress and its factors in Bangladesh: A perception-based study. Heliyon. 2020;6: e04399. doi:10.1016/j.heliyon.2020.e04399

34. Li X, Wu H, Meng F, Li L, Wang Y, Zhou M. Relations of COVID-19-Related stressors and social support with Chinese college students' psychological response during the COVID-19 pandemic. Front Psychiatry. 2020;11: 551315. doi:10.3389/fpsyt.2020.551315

35. van der Heide A, Meinders MJ, Bloem BR, Helmich RC. The impact of the COVID-19 pandemic on psychological distress, physical activity, and symptom severity in Parkinson's Disease. J Park Dis. 2020;10: 1355-1364. doi:10.3233/JPD-202251

36. Lotzin A, Aakvaag H, Acquarini E, Ajdukovic D, Ardino V, Böttche M, et al. Stressors, coping and symptoms of adjustment disorder in the course of COVID-19 pandemic - The European Society for Traumatic Stress Studies (ESTSS) pan-European study. 2020. doi:10.17605/OSF.IO/8XHYG

37. Samuels P. Advice on exploratory factor analysis. 2017.

38. Field A. Discovering statistics using IBM SPSS statistics. sage; 2013.

39. Kline RB. Principles and practice of structural equation modeling. 4th ed. New York: Guilford Press; 2015.

40. Schermelleh-Engel K, Moosbrugger H, Müller H. Evaluating the fit of structural equation models: Tests of significance and descriptive Goodness-ofFit measures. Methods Psychol Res. 2003;8: 23-74.

41. Hair Jr. JF, Black WC, Babin BJ, Anderson RE. Multivariate data analysis. 8th ed. Andover, Hampshire: Cengage Learning EMEA; 2019.

42. Bagozzi RR, Yi Y. On the evaluation of structural equation models. 1988; 21.

43. Fornell C, Larcker DF. Evaluating structural equation models with unobservable variables and measurement error. J Mark Res. 1981;18: 39-50. doi:https://doi.org/10.1177/002224378101800104

44. Ponterotto JG, Ruckdeschel DE. An overview of coefficient alpha and a reliability matrix for estimating adequacy of internal consistency coefficients with psychological research measures. Percept Mot Skills. 2007;105: 997-1014. doi:https://doi.org/10.2466/pms.105.3.997-1014

45. Kline P. Handbook of Psychological Testing. Routledge; 2013.

46. Krohne HW, Hock M, Heuer H, Rösler F, Tack WH, editors. Psychologische Diagnostik: Grundlagen und Anwendungsfelder.

47. Cudeck R, O’Dell LL. Applications of standard error estimates in unrestricted factor analysis: Significance tests for factor loadings and correlations. Psychol Bull. 1994;115: 475.

\section{Tables}

Table 1

Sample Characteristics

Page 10/18 


\begin{tabular}{|c|c|c|c|c|}
\hline \multirow[b]{2}{*}{ Sociodemographic variable } & \multicolumn{2}{|c|}{$\begin{array}{l}\text { German sample } \\
n=2760\end{array}$} & \multicolumn{2}{|c|}{$\begin{array}{l}\text { Austrian sample } \\
n=1021\end{array}$} \\
\hline & $M$ & $S D$ & $M$ & $S D$ \\
\hline Age & 40.79 & 12.43 & 45.22 & 14.48 \\
\hline Gender & $N$ & $\%$ & $N$ & $\%$ \\
\hline Male & 792 & 28.7 & 345 & 33.8 \\
\hline Female & 1958 & 70.9 & 670 & 65.6 \\
\hline Other & 10 & 0.36 & 6 & 0.59 \\
\hline \multicolumn{5}{|l|}{ Community } \\
\hline Large city & 1595 & 57.8 & 675 & 66.1 \\
\hline Small city or town & 610 & 22.1 & 180 & 17.6 \\
\hline Suburb near a large city & 310 & 11.2 & 71 & 6.95 \\
\hline Rural area & 245 & 8.88 & 95 & 9.30 \\
\hline \multicolumn{5}{|l|}{ Relationship status ${ }^{a, b}$} \\
\hline Single & 618 & 27.1 & 213 & 25.7 \\
\hline Stable relationship (living together) & 1423 & 62.4 & 496 & 59.9 \\
\hline Stable relationship (living separately) & 194 & 8.51 & 93 & 11.2 \\
\hline Temporary relationship(s) & 46 & 2.02 & 26 & 3.14 \\
\hline \multicolumn{5}{|l|}{ Education level } \\
\hline$<10$ years of schooling & 8 & 0.29 & 17 & 1.67 \\
\hline$\geq 10$ years of schooling & 348 & 12.6 & 150 & 14.7 \\
\hline Vocational studies & 996 & 36.1 & 319 & 31.2 \\
\hline Completed studies & 1408 & 51.0 & 535 & 52.4 \\
\hline \multicolumn{5}{|l|}{ Working situation } \\
\hline Employed full-time & 1351 & 48.9 & 558 & 54.7 \\
\hline Employed part-time & 781 & 28.3 & 267 & 26.2 \\
\hline Vocational training or study & 414 & 15.0 & 116 & 11.4 \\
\hline Self-employed & 99 & 3.59 & 74 & 7.25 \\
\hline Freelancer & 76 & 2.75 & 31 & 3.04 \\
\hline Retired & 112 & 4.06 & 111 & 10.9 \\
\hline Seeking work & 69 & 2.50 & 16 & 1.57 \\
\hline Other & 178 & 6.45 & 17 & 1.67 \\
\hline \multicolumn{5}{|l|}{ Corona virus infection other } \\
\hline Loved ones & 182 & 6.59 & 68 & 6.66 \\
\hline Someone else I know personally & 920 & 33.3 & 395 & 38.7 \\
\hline No & 1694 & 61.4 & 582 & 57.0 \\
\hline \multicolumn{5}{|l|}{ Coronavirus infection self } \\
\hline Yes (recovered) & 21 & 0.76 & 8 & 0.78 \\
\hline No & 2739 & 99.2 & 1013 & 99.2 \\
\hline \multicolumn{5}{|l|}{$\begin{array}{l}\text { Risk for severe or life-threatening } \\
\text { symptoms of the coronavirus disease }\end{array}$} \\
\hline Yes & 589 & 21.3 & 164 & 16.1 \\
\hline
\end{tabular}

Page 11/18 


\begin{tabular}{|lcccc|}
\hline No & 2171 & 78.7 & 857 & 83.9 \\
\hline Mental disorder diagnosis & & & & \\
\hline Yes (currently affected) & 222 & 8.04 & 73 & 7.15 \\
\hline Yes (recovered) & 412 & 14.9 & 150 & 14.7 \\
\hline No & 2126 & 77.0 & 798 & 78.2 \\
\hline Note. $^{a} n=2281$ for the German sample, & & \\
&
\end{tabular}

Table 2

Means, Standard Deviations, Skewness and Kurtosis for the Pandemic Stressors Scale Items 


\begin{tabular}{|c|c|c|c|c|c|c|c|c|c|}
\hline \multirow[b]{2}{*}{ Item } & & \multicolumn{4}{|c|}{$\begin{array}{l}\text { German sample } \\
(N=2760)\end{array}$} & \multicolumn{4}{|c|}{$\begin{array}{l}\text { Austrian sample } \\
(N=1021)\end{array}$} \\
\hline & & $M$ & $S D$ & Skew & Kurt. & $M$ & $S D$ & Skew & Kurt. \\
\hline Item 1 & Loss of childcare & 0.51 & 1.03 & 1.73 & 1.31 & 0.41 & 0.93 & 2.09 & 2.79 \\
\hline Item 2 & Difficulties with combining work with childcare & 0.49 & 1.02 & 1.78 & 1.47 & 0.44 & 0.96 & 1.95 & 2.17 \\
\hline Item 3 & (Threat of) income loss & 0.92 & 1.15 & 0.81 & -0.89 & 0.53 & 0.96 & 1.62 & 1.23 \\
\hline Item 4 & (Threat of) job loss & 0.82 & 1.13 & 0.98 & -0.62 & 0.41 & 0.89 & 2.06 & 2.88 \\
\hline Item 5 & Reduced working hours & 0.70 & 1.07 & 1.21 & -0.07 & 0.35 & 0.79 & 2.30 & 4.22 \\
\hline Item 6 & Not being able to work & 0.52 & 1.00 & 1.68 & 1.26 & 0.30 & 0.77 & 2.58 & 5.46 \\
\hline Item 7 & Insufficient financial support by the government & 0.46 & 0.89 & 1.85 & 2.17 & 0.41 & 0.86 & 2.06 & 2.99 \\
\hline Item 8 & Restricted face-to-face contact with loved ones & 1.75 & 0.99 & -0.20 & -1.05 & 1.59 & 1.00 & -0.02 & -1.08 \\
\hline Item 9 & Restricted face-to-face contact with others & 1.33 & 0.97 & 0.26 & -0.89 & 1.15 & 0.98 & 0.46 & -0.79 \\
\hline Item 10 & Social isolation & 1.42 & 1.03 & 0.14 & -1.11 & 1.16 & 1.04 & 0.46 & -0.97 \\
\hline Item 11 & Restricted physical closeness to loved ones & 1.46 & 1.10 & 0.09 & -1.31 & 1.31 & 1.08 & 0.26 & -1.21 \\
\hline Item 12 & Infection of loved ones with the coronavirus & 0.87 & 1.10 & 0.85 & -0.78 & 0.92 & 1.11 & 0.79 & -0.85 \\
\hline Item 13 & Death of a loved one due to the coronavirus infection & 0.73 & 1.13 & 1.15 & -0.32 & 0.78 & 1.14 & 1.07 & -0.49 \\
\hline Item 14 & My own infection with the coronavirus & 0.34 & 0.74 & 2.22 & 4.14 & 0.34 & 0.73 & 2.19 & 3.94 \\
\hline Item 15 & Poor information from the government & 0.85 & 0.95 & 0.83 & -0.37 & 0.99 & 0.98 & 0.60 & -0.75 \\
\hline Item 16 & Poor crisis management of the government & 0.82 & 0.96 & 0.91 & -0.29 & 0.96 & 0.97 & 0.64 & -0.69 \\
\hline Item 17 & Media coverage of the coronavirus pandemic & 1.52 & 0.99 & -0.01 & -1.04 & 1.31 & 1.02 & 0.23 & -1.06 \\
\hline Item 18 & No place of retreat & 0.64 & 0.97 & 1.31 & 0.44 & 0.56 & 0.92 & 1.50 & 0.99 \\
\hline Item 19 & Conflicts at home & 0.59 & 0.88 & 1.37 & 0.85 & 0.48 & 0.82 & 1.67 & 1.86 \\
\hline Item 20 & Restricted housing conditions & 0.56 & 0.89 & 1.49 & 1.11 & 0.54 & 0.90 & 1.58 & 1.32 \\
\hline Item 21 & Fear of getting infected with the coronavirus & 1.26 & 0.92 & 0.32 & -0.72 & 1.15 & 0.89 & 0.39 & -0.61 \\
\hline Item 22 & Fear of infecting others with the coronavirus & 1.31 & 1.09 & 0.20 & -1.26 & 1.23 & 1.09 & 0.30 & -1.24 \\
\hline Item 23 & Uncertainty about duration and risks of the pandemic & 2.02 & 0.85 & -0.49 & -0.49 & 1.79 & 0.92 & -0.27 & -0.81 \\
\hline Item 24 & Fear that loved ones get infected with the coronavirus & 1.86 & 0.97 & -0.37 & -0.92 & 1.70 & 1.03 & -0.24 & -1.08 \\
\hline Item 25 & Restricted access to regular health care or medication & 0.47 & 0.76 & 1.66 & 2.12 & 0.66 & 0.87 & 1.11 & 0.25 \\
\hline Item 26 & Restricted access to goods, e.g., food, water, clothing & 0.53 & 0.79 & 1.42 & 1.27 & 0.32 & 0.66 & 2.16 & 4.25 \\
\hline Item 27 & Insufficient capacity of the health care system & 0.83 & 0.98 & 0.89 & -0.38 & 0.87 & 1.02 & 0.80 & -0.64 \\
\hline Item 28 & Restricted leisure activity & 1.58 & 0.99 & -0.06 & -1.04 & 1.33 & 1.00 & 0.17 & -1.04 \\
\hline Item 29 & Restricted everyday activity & 1.40 & 0.94 & 0.16 & -0.86 & 1.04 & 0.91 & 0.48 & -0.67 \\
\hline Item 30 & Restricted private travelling & 1.63 & 1.07 & -0.14 & -1.23 & 1.59 & 1.11 & -0.11 & -1.34 \\
\hline
\end{tabular}

Table 3

Factor Loadings in the German sample $(N=2760)$ 


\begin{tabular}{|c|c|c|c|c|c|c|c|c|c|c|}
\hline Item & $\begin{array}{l}\text { Item } \\
\text { description }\end{array}$ & $\begin{array}{l}\text { Problems } \\
\text { with } \\
\text { Childcare }\end{array}$ & $\begin{array}{l}\text { Work- } \\
\text { related } \\
\text { Problems }\end{array}$ & $\begin{array}{l}\text { Restricted } \\
\text { Face-to- } \\
\text { Face } \\
\text { Contact }\end{array}$ & $\begin{array}{l}\text { Burden } \\
\text { of } \\
\text { Infection }\end{array}$ & $\begin{array}{l}\text { Crisis } \\
\text { Managment } \\
\text { and Comm. }\end{array}$ & $\begin{array}{l}\text { Difficult } \\
\text { Housing } \\
\text { Condition }\end{array}$ & $\begin{array}{l}\text { Fear of } \\
\text { infection }\end{array}$ & $\begin{array}{l}\text { Restricted } \\
\text { Access to } \\
\text { Resources }\end{array}$ & $\begin{array}{l}\text { Restricted } \\
\text { Activity }\end{array}$ \\
\hline $\begin{array}{l}\text { Item } \\
1\end{array}$ & $\begin{array}{l}\text { Loss of } \\
\text { childcare }\end{array}$ & 0.949 & & & & & & & & \\
\hline $\begin{array}{l}\text { Item } \\
2\end{array}$ & $\begin{array}{l}\text { Difficulties with } \\
\text { combining work } \\
\text { with childcare }\end{array}$ & 0.927 & & & & & & & & \\
\hline $\begin{array}{l}\text { Item } \\
3\end{array}$ & $\begin{array}{l}\text { (Threat of) } \\
\text { income loss }\end{array}$ & & 0.930 & & & & & & & \\
\hline $\begin{array}{l}\text { Item } \\
4\end{array}$ & $\begin{array}{l}\text { (Threat of) job } \\
\text { loss }\end{array}$ & & 0.833 & & & & & & & \\
\hline $\begin{array}{l}\text { Item } \\
5\end{array}$ & $\begin{array}{l}\text { Reduced } \\
\text { working hours }\end{array}$ & & 0.688 & & & & & & & \\
\hline $\begin{array}{l}\text { Item } \\
6\end{array}$ & $\begin{array}{l}\text { Not being able } \\
\text { to work }\end{array}$ & & 0.621 & & & & & & & \\
\hline $\begin{array}{l}\text { Item } \\
7\end{array}$ & $\begin{array}{l}\text { Insufficient } \\
\text { financial } \\
\text { support by the } \\
\text { government }\end{array}$ & & 0.603 & & & & & & & \\
\hline $\begin{array}{l}\text { Item } \\
8\end{array}$ & $\begin{array}{l}\text { Restricted face- } \\
\text { to-face contact } \\
\text { with loved ones }\end{array}$ & & & 0.841 & & & & & & \\
\hline $\begin{array}{l}\text { Item } \\
9\end{array}$ & $\begin{array}{l}\text { Restricted face- } \\
\text { to-face contact } \\
\text { with others }\end{array}$ & & & 0.758 & & & & & & -0.499 \\
\hline $\begin{array}{l}\text { Item } \\
10\end{array}$ & Social isolation & & & 0.798 & & & & & & -0.458 \\
\hline $\begin{array}{l}\text { Item } \\
11\end{array}$ & $\begin{array}{l}\text { Restricted } \\
\text { physical } \\
\text { closeness to } \\
\text { loved ones }\end{array}$ & & & 0.734 & & & & & & -0.340 \\
\hline $\begin{array}{l}\text { Item } \\
12\end{array}$ & $\begin{array}{l}\text { Infection of } \\
\text { loved ones with } \\
\text { the coronavirus }\end{array}$ & & & & 0.834 & & & & & \\
\hline $\begin{array}{l}\text { Item } \\
13\end{array}$ & $\begin{array}{l}\text { Death of a loved } \\
\text { one due to the } \\
\text { coronavirus inf. }\end{array}$ & & & & 0.819 & & & & & \\
\hline $\begin{array}{l}\text { Item } \\
14\end{array}$ & $\begin{array}{l}\text { My own } \\
\text { infection with } \\
\text { the coronavirus }\end{array}$ & & & & 0.486 & & & & & \\
\hline $\begin{array}{l}\text { Item } \\
15\end{array}$ & $\begin{array}{l}\text { Poor } \\
\text { information } \\
\text { from the } \\
\text { government }\end{array}$ & & & & & 0.845 & & & & \\
\hline $\begin{array}{l}\text { Item } \\
16\end{array}$ & $\begin{array}{l}\text { Poor crisis } \\
\text { management of } \\
\text { the government }\end{array}$ & & & & & 0.786 & & & & \\
\hline $\begin{array}{l}\text { Item } \\
17\end{array}$ & $\begin{array}{l}\text { Media coverage } \\
\text { of the } \\
\text { coronavirus } \\
\text { pandemic }\end{array}$ & & & & & 0.458 & & & & \\
\hline $\begin{array}{l}\text { Item } \\
18\end{array}$ & $\begin{array}{l}\text { No place of } \\
\text { retreat }\end{array}$ & 0.464 & & & & & 0.883 & & & \\
\hline $\begin{array}{l}\text { Item } \\
19\end{array}$ & $\begin{array}{l}\text { Conflicts at } \\
\text { home }\end{array}$ & & & & & & 0.639 & & & \\
\hline $\begin{array}{l}\text { Item } \\
20\end{array}$ & $\begin{array}{l}\text { Restricted } \\
\text { housing } \\
\text { conditions }\end{array}$ & & & & & & 0.604 & & & \\
\hline $\begin{array}{l}\text { Item } \\
21\end{array}$ & $\begin{array}{l}\text { Fear of getting } \\
\text { infected with } \\
\text { the coronavirus }\end{array}$ & & & & 0.409 & & & 0.770 & & \\
\hline
\end{tabular}




\begin{tabular}{|c|c|c|c|c|c|c|c|c|c|c|}
\hline Item & $\begin{array}{l}\text { Item } \\
\text { description }\end{array}$ & $\begin{array}{l}\text { Problems } \\
\text { with } \\
\text { Childcare }\end{array}$ & $\begin{array}{l}\text { Work- } \\
\text { related } \\
\text { Problems }\end{array}$ & $\begin{array}{l}\text { Restricted } \\
\text { Face-to- } \\
\text { Face } \\
\text { Contact }\end{array}$ & $\begin{array}{l}\text { Burden } \\
\text { of } \\
\text { Infection }\end{array}$ & $\begin{array}{l}\text { Crisis } \\
\text { Managment } \\
\text { and Comm. }\end{array}$ & $\begin{array}{l}\text { Difficult } \\
\text { Housing } \\
\text { Condition }\end{array}$ & $\begin{array}{l}\text { Fear of } \\
\text { infection }\end{array}$ & $\begin{array}{l}\text { Restricted } \\
\text { Access to } \\
\text { Resources }\end{array}$ & $\begin{array}{l}\text { Restricted } \\
\text { Activity }\end{array}$ \\
\hline $\begin{array}{l}\text { Item } \\
22\end{array}$ & $\begin{array}{l}\text { Fear of infecting } \\
\text { others with the } \\
\text { coronavirus }\end{array}$ & & & & & & & 0.628 & & \\
\hline $\begin{array}{l}\text { Item } \\
24\end{array}$ & $\begin{array}{l}\text { Fear that loved } \\
\text { ones get } \\
\text { infected }\end{array}$ & & & & & & & 0.437 & & \\
\hline $\begin{array}{l}\text { Item } \\
26\end{array}$ & $\begin{array}{l}\text { Restricted } \\
\text { access to } \\
\text { goods, e.g., } \\
\text { food, water }\end{array}$ & & & & & & & & 0.559 & \\
\hline $\begin{array}{l}\text { Item } \\
27\end{array}$ & $\begin{array}{l}\text { Insufficient } \\
\text { capacity of the } \\
\text { health care } \\
\text { system }\end{array}$ & & & & & & & & 0.486 & \\
\hline $\begin{array}{l}\text { Item } \\
28\end{array}$ & $\begin{array}{l}\text { Restricted } \\
\text { leisure activity }\end{array}$ & & & 0.463 & & & & & & -0.841 \\
\hline $\begin{array}{l}\text { Item } \\
29\end{array}$ & $\begin{array}{l}\text { Restricted } \\
\text { everyday } \\
\text { activity }\end{array}$ & & & 0.416 & & & & & & -0.648 \\
\hline $\begin{array}{l}\text { Item } \\
30\end{array}$ & $\begin{array}{l}\text { Restricted } \\
\text { private } \\
\text { travelling }\end{array}$ & & & & & & & & & -0.559 \\
\hline
\end{tabular}

Notes. Factor loadings $>.40$ are reported

Table 4

Global Fit Indices of the Confirmatory Factor Analysis for Model 1 and Model 2 in the Austrian Study Sample ( $N=1021$ participants)

\begin{tabular}{|c|c|c|c|c|c|c|c|c|c|c|}
\hline Global Fit Index & $\chi^{2}$ & df & $p$ & normed $\chi^{2}$ & RMSA & $p$ RMSA & RMSA $90 \% \mathrm{Cl}$ & SRMR & TLI & CFI \\
\hline Model 1 & 1443.28 & 369 & $<.001$ & 3.91 & .053 & .026 & $.051-.056$ & .055 & .904 & .919 \\
\hline Model 2 & 1948.51 & 396 & $<.001$ & 4.92 & .062 & $<.001$ & $.059-.065$ & .074 & .871 & .883 \\
\hline
\end{tabular}

Table 5

Local Goodness of Fit Indices on the Indicator Level in the Austrian Sample ( $N=1021)$ 


\begin{tabular}{|c|c|c|c|c|}
\hline \multirow[t]{2}{*}{ Scale } & \multicolumn{2}{|c|}{ Factor loading } & \multicolumn{2}{|c|}{ Communality } \\
\hline & Model 1 & Model 2 & Model 1 & Model 2 \\
\hline \multicolumn{5}{|c|}{ Problems with Childcare } \\
\hline Item 1 & .91 & .94 & .83 & .89 \\
\hline Item 2 & .97 & .93 & .94 & .87 \\
\hline \multicolumn{5}{|c|}{ Work-related Problems } \\
\hline Item 3 & .90 & .91 & .82 & .82 \\
\hline Item 4 & .82 & .82 & .67 & .67 \\
\hline Item 5 & .59 & .59 & .35 & .35 \\
\hline Item 6 & .69 & .69 & .48 & .48 \\
\hline Item 7 & .72 & .72 & .52 & .51 \\
\hline \multicolumn{5}{|c|}{ Restricted Face-to-Face Contact } \\
\hline Item 8 & .83 & .83 & .68 & .68 \\
\hline Item 9 & .75 & .74 & .56 & .55 \\
\hline Item 10 & .79 & .79 & .63 & .63 \\
\hline Item 11 & .72 & .73 & .52 & .53 \\
\hline \multicolumn{5}{|c|}{ Burden of Infection } \\
\hline Item 12 & .87 & .88 & .75 & .77 \\
\hline Item 13 & .79 & .79 & .62 & .62 \\
\hline Item 14 & .55 & .54 & .31 & .29 \\
\hline \multicolumn{5}{|c|}{ Crisis Management and Communication } \\
\hline Item 15 & .84 & .84 & .71 & .71 \\
\hline Item 16 & .82 & .82 & .68 & .67 \\
\hline Item 17 & .55 & .55 & .30 & .30 \\
\hline \multicolumn{5}{|c|}{ Difficult Housing Condition } \\
\hline Item 18 & .92 & .90 & .84 & .81 \\
\hline Item 19 & .67 & .66 & .44 & .44 \\
\hline Item 20 & .66 & .67 & .43 & .45 \\
\hline \multicolumn{5}{|c|}{ Fear of Infection } \\
\hline Item 21 & .61 & .60 & .37 & .36 \\
\hline Item 22 & .66 & .65 & .44 & .43 \\
\hline Item 23 & .54 & .59 & .30 & .34 \\
\hline Item 24 & .80 & .78 & .64 & .61 \\
\hline \multicolumn{5}{|c|}{ Restricted Access to Resources } \\
\hline Item 25 & .69 & .72 & .47 & .52 \\
\hline Item 26 & .52 & .54 & .27 & .29 \\
\hline Item 27 & .63 & .59 & .40 & .35 \\
\hline \multicolumn{5}{|c|}{ Restricted Activity } \\
\hline Item 28 & .82 & .80 & .67 & .63 \\
\hline Item 29 & .67 & .70 & .45 & .49 \\
\hline Item 30 & .57 & .56 & .32 & .32 \\
\hline
\end{tabular}




\begin{tabular}{|lllll|}
\hline Scale & \multicolumn{2}{l}{ Factor loading } & \multicolumn{2}{l|}{ Communality } \\
\cline { 2 - 5 } & Model 1 & Model 2 & Model 1 & Model 2 \\
\hline Problems with Childcare & - & .24 & - & - \\
\hline Work-related Problems & - & .41 & - & - \\
\hline Restricted Face-to-Face Contact & - & .79 & - & - \\
\hline Burden of Infection & - & .42 & - & - \\
\hline Crisis Management and Communication & - & .56 & - & - \\
\hline Difficult Housing Condition & - & .49 & - & - \\
\hline Fear of Infection & - & .59 & - & - \\
\hline Restricted Access to Resources & - & .60 & - & - \\
\hline Restricted Activity & - & .72 & - & - \\
\hline
\end{tabular}

Table 6

Local Goodness of Fit Indices on The Factor Level in the Austrian Sample $(N=1021)$

\begin{tabular}{|c|c|c|c|c|c|c|c|c|c|c|c|c|}
\hline \multirow[t]{2}{*}{ Scale } & \multirow[t]{2}{*}{$\mathrm{FR}^{\mathrm{a}}$} & \multirow[t]{2}{*}{$\mathrm{AVE}^{\mathrm{a}}$} & \multicolumn{9}{|c|}{ Coefficient of Determination $\left(R^{2}\right)$} & \multirow{2}{*}{$\begin{array}{l}\text { Discriminant } \\
\text { from } \\
\left(\mathrm{AVE}>R^{2}\right)^{\mathrm{b}}\end{array}$} \\
\hline & & & $\mathrm{CC}$ & WP & RF & $\mathrm{BI}$ & MC & $\mathrm{HC}$ & $\mathrm{FI}$ & AR & RA & \\
\hline Problems with Childcare (CC) & .94 & .88 & 1 & .02 & .02 & .00 & .01 & .20 & .01 & .02 & .01 & all \\
\hline Work-related Problems (WP) & .86 & .57 & .02 & 1 & .09 & .09 & .07 & .05 & .05 & .06 & .06 & all \\
\hline Restricted Face-to-Face Contact (RF) & .86 & .60 & .02 & .09 & 1 & .08 & .16 & .14 & .21 & .17 & .48 & all \\
\hline Burden of Infection (BI) & .79 & .56 & .00 & .09 & .08 & 1 & .04 & .01 & .39 & .12 & .01 & all \\
\hline $\begin{array}{l}\text { Crisis Management and Communication } \\
\text { (MC) }\end{array}$ & .79 & .56 & .01 & .07 & .16 & .04 & 1 & .10 & .07 & .24 & .17 & all \\
\hline Difficult Housing Condition (HC) & $\begin{array}{l}.80 \\
(.79)\end{array}$ & .57 & .20 & .05 & .14 & .01 & .10 & 1 & .05 & .05 & .11 & all \\
\hline Fear of Infection (FI) & .75 & $\begin{array}{l}.44 \\
(.43)\end{array}$ & .01 & .05 & .21 & .39 & .07 & .05 & 1 & .18 & .07 & all \\
\hline Restricted Access to Resources (AR) & .65 & $\begin{array}{l}.38 \\
(.39)\end{array}$ & .02 & .06 & .17 & .12 & .24 & .05 & .18 & 1 & .15 & all \\
\hline Restricted Activity (RA) & .73 & .48 & .01 & .06 & .48 & .01 & .17 & .11 & .07 & .15 & 1 & all, but SC \\
\hline Pandemic Stressors (PS) & .97 & .55 & - & - & - & - & - & - & - & - & - & - \\
\hline
\end{tabular}

Table 7

Internal Consistency, Discrimination Index and Difficulty Index in the Austrian Sample $(N=1021)$ 


\begin{tabular}{|c|c|c|c|c|c|c|c|c|c|c|}
\hline \multirow[t]{2}{*}{ Scale } & \multirow[t]{2}{*}{ Items $(n)$} & \multirow[t]{2}{*}{$M$} & \multirow[t]{2}{*}{$S D$} & \multirow[t]{2}{*}{ Cronbach's a } & \multicolumn{3}{|c|}{ Item discrimination $\left(r_{i t}\right)$} & \multicolumn{3}{|c|}{ Item difficulty $(P)$} \\
\hline & & & & & $M$ & Min & Max & $M$ & Min & Max \\
\hline Work-related Problems & 5 & 2.00 & 3.44 & .86 & .69 & .57 & .81 & .13 & .10 & .18 \\
\hline Restricted Face-to-Face Contact & 4 & 5.21 & 3.42 & .85 & .70 & .66 & .75 & .43 & .38 & .53 \\
\hline Crisis Management and Communication & 3 & 3.27 & 2.45 & .77 & .60 & .47 & .67 & .36 & .32 & .44 \\
\hline Difficult Housing Condition & 3 & 1.57 & 2.20 & .78 & .62 & .56 & .73 & .18 & .16 & .19 \\
\hline Fear of Infection & 4 & 5.87 & 2.97 & .74 & .54 & .46 & .65 & .49 & .38 & .60 \\
\hline Restricted Access to Resources & 3 & 1.86 & 1.96 & .63 & .45 & .40 & .52 & .21 & .11 & .29 \\
\hline
\end{tabular}

